\title{
Acoustic properties of perforates under high level multi-tone excitation
}

\author{
Hans Bodén \\ Linné Flow Centre \\ MWL, Aeronautical and Vehicle Engineering, KTH, \\ S-100 44 Stockholm, Sweden
}

\begin{abstract}
This paper discusses the effect of high level multi-tone acoustic excitation on the acoustic properties of perforates. It is based on a large experimental study of the nonlinear properties of these types of samples without mean grazing or bias flow. Compared to previously published results the present investigation concentrates on the effect of multiple harmonics. It is known from previous studies that high level acoustic excitation at one frequency will change the acoustic impedance of perforates at other frequencies, thereby changing the boundary condition seen by the acoustic waves. This effect could be used to change the impedance boundary conditions and for instance increase the absorption. It could obviously also pose a problem for the correct modelling of sound transmission through ducts lined with such impedance surfaces. Experimental results are compared to a quasi-stationary model. The effect of the combination of frequency components and phase in the excitation signal is studied.
\end{abstract}

\section{Introduction}

$\mathrm{T}$ here is a large number of papers on the effect of high level acoustic excitation on the acoustic properties of perforates and orifice plates ${ }^{1-18}$. Orifice plates and perforates appear in many technical applications where they are exposed to a combination of high acoustic excitation levels and either grazing or bias flow or a combination. Examples are automotive mufflers and aircraft engine liners. Non-linear losses are associated with vortex shedding at the outlet side of the orifice or perforate openings. In the linear case the impedance is independent of the sound field but when the sound pressure level is high the perforate impedance will be dependent on the acoustic particle velocity in the holes. For pure tone excitation the impedance will be controlled by the acoustic particle velocity at that frequency. If the acoustic excitation is random or periodic with multiple harmonics the impedance at a certain frequency will depend on the particle velocity at other frequencies ${ }^{17-18} \cdot \operatorname{In}^{18}$ the effect of mainly two-tone excitation on the acoustic properties of perforates was discussed and the present paper discusses the effect of high level multitone acoustic excitation. It is based on an experimental study of the nonlinear properties of these types of samples without mean grazing or bias flow. It is known from previous studies that high level acoustic excitation at one frequency will change the acoustic impedance of perforates at other frequencies, thereby changing the boundary condition seen by the acoustic waves. This effect could be used to change the impedance boundary conditions and for instance increase the absorption, as in the so-called zero mass-flow liner ${ }^{19}$. This effect can also pose a problem for the correct modelling of sound transmission through ducts lined with such impedance surfaces. The present paper will study the effect of harmonic or non-harmonic excitation as well as the influence of combination of signal phase.

\section{Perforate impedance model}

The model used here takes the starting point in the model presented by Cummings ${ }^{7}$. This model can excluding bias flow effects be written

$$
l(t) \frac{d V(t)}{d t}+\frac{1}{2}\left(\frac{V(t)}{C_{D}}\right) \cdot\left|\frac{V(t)}{C_{D}}\right|=\frac{\Delta p(t)}{\rho_{0}},
$$


where $l(t)$ is an effective orifice thickness including end corrections which can be time varying, $V(t)$ is the fluctuating acoustic velocity in the orifice, $C_{D}$ is a discharge coefficient to consider the vena contracta effect and $\Delta p(t)$ is the fluctuating pressure difference over the orifice. In the model according to Eq. (1) linear viscous losses are neglected. Such a term can be added either from theory ${ }^{16}$ or from experimental data giving

$$
l(t) \frac{d V(t)}{d t}+\frac{1}{2}\left(\frac{V(t)}{C_{D}}\right) \cdot\left|\frac{V(t)}{C_{D}}\right|+R_{L} V(t)=\frac{\Delta p(t)}{\rho_{0}} .
$$

In the article by Cummings ${ }^{7}$ an empirical expression for the time varying effective orifice length was presented

$$
l(t)=l_{0}+\frac{l_{W}+l_{0}}{1+\frac{\left(L_{V}(t) / d\right)^{1.585}}{3}},
$$

where $l_{0}$ is the end correction on one side of the orifice, $l_{W}$ is the orifice length, $L_{V}(t)$ is a time varying jet length caused by the high level acoustic excitation and $d$ is the orifice diameter. Cummings suggested that the jet length should be estimated from

$$
L_{V}(t)=\int_{0}^{\tau} V(t) d t
$$

where $\tau$ is the time from the beginning of the previous acoustic half cycle after $V(t)$ has changed sign. Here the result of using Eq. (4) has been compared to the assumption that $L_{V}$ does not vary with time but only with the level of acoustic excitation such that

$$
L_{V}=\int_{0}^{T / 2}|V(t)| d t
$$

It was found by comparison with experimental data that a modified version of Eq. (3), shown in Eq. (6), gave a better agreement with experimental results for some perforates. This has, together with jet length estimation using Eq. (5) been used for some of the simulation studies presented in section IIII.

$$
l(t)=l_{0}+\frac{l_{W}+l_{0}}{1+\frac{\left(L_{V}(t) / d\right)^{1.2}}{24}},
$$

\section{Experimental setup}

The experimental data presented were obtained using an impedance tube with the perforate sample mounted at the end and an open termination behind the perforate sample. The sample was mounted using a holder causing a slight area reduction. The impedance change caused by the holder was measured separately and deducted from the perforate sample results. Three quarter inch condenser microphones were used with microphone separations $0.05 \mathrm{~m}$ and $0.3 \mathrm{~m}$. The distance between the sample and the nearest microphone was $0.15 \mathrm{~m}$.

Tonal excitation was used either with single tone excitation or with a combination of tones with different frequencies. Measurements in the impedance tube were made for four different circular hole perforate samples, as specified in Table 1. The perforate samples studied are described in Table 1 in terms of their hole diameter $(d)$, plate thickness $\left(l_{w}\right)$ and porosity $(\sigma)$. Results obtained for sample P2 with porosity $\sigma=0.032$ and sample P4 with $\sigma=0.032$ will be presented in this paper. 
Table 1. Specification of circular hole perforate samples tested in the impedance tube.

\begin{tabular}{|l|l|l|l|}
\hline Sample & $\mathrm{d}[\mathrm{mm}]$ & $\mathrm{t}[\mathrm{mm}]$ & $\sigma$ \\
\hline P1 & 3 & 1 & 0.28 \\
\hline P2 & 2 & 1.5 & 0.032 \\
\hline P3 & 2 & 2 & 0.086 \\
\hline P4 & 1 & 2 & 0.020 \\
\hline
\end{tabular}

\section{Results and discussion}

\section{A. Single tone excitation}

Figure 1 shows the normalized perforate impedance of sample P2 with porosity 0.032 , obtained using single tone excitation at $110 \mathrm{~Hz}$, plotted against peak particle velocity in the holes. A comparison is made between experimental results and simulated results obtained using Cummings equation (2) with the equivalent orifice thickness calculated using Eq. (4) and Eq. (6). Figure 2 shows the corresponding results for sample P4 with porosity 0.02. The agreement between simulated and experimental results is fairly good.

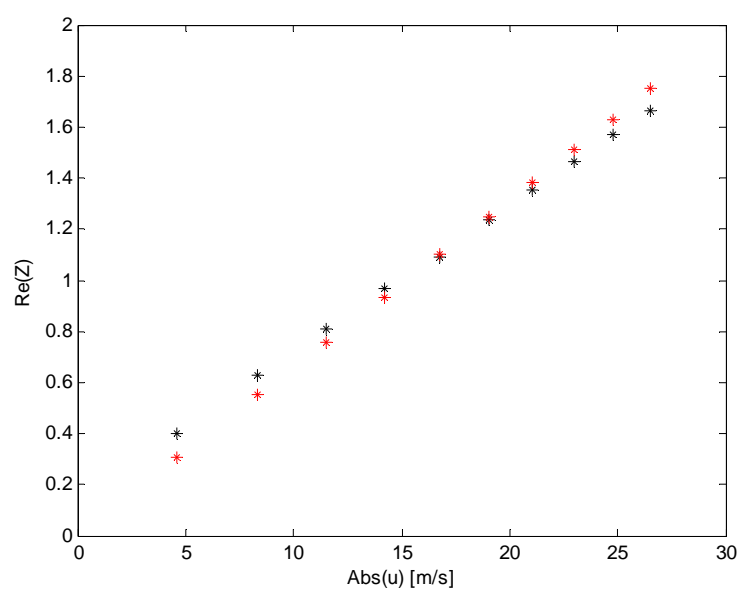

a)

Figure 1. Normalized impedance at $110 \mathrm{~Hz}$ for perforate sample with $3.2 \%$ porosity, for single tone excitation at $110 \mathrm{~Hz}$, plotted against particle velocity in the holes: black - measurement, red - simulation; solid lines imaginary parts obtained assuming: $l=I_{0}, I=I_{0}+I_{W}$ and $I=2 l_{0}+l_{W}$; a) Real part, b) Imaginary part. 


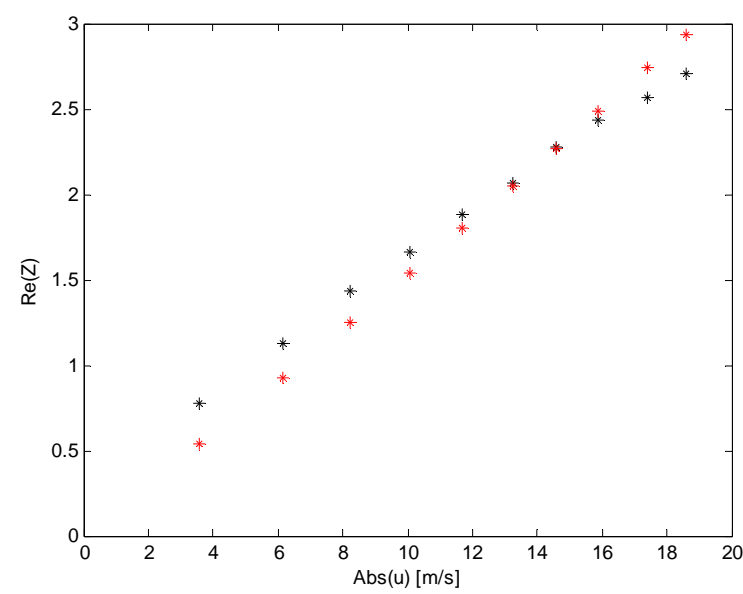

a)

Figure 2. Normalized impedance at $110 \mathrm{~Hz}$ for perforate sample with $2 \%$ porosity, for single tone excitation at $110 \mathrm{~Hz}$, plotted against particle velocity in the holes: black - measurement, red - simulation; solid lines imaginary parts obtained assuming: $I=I_{0}, I=I_{0}+I_{W}$ and $I=2 l_{0}+l_{W}$; a) Real part, b) Imaginary part.

\section{B. Multi tone excitation}

In this section experimental and simulation results for multi tone excitation are presented, starting with two tone excitation shown in Fig. 3 and 4. It can be seen that the simulation still gives a reasonably fair prediction of a large part of the resistance results but with some deviation while the reactance results agree less well. The reason for this scattering in the experimental results will be investigated in the remainder of this section.

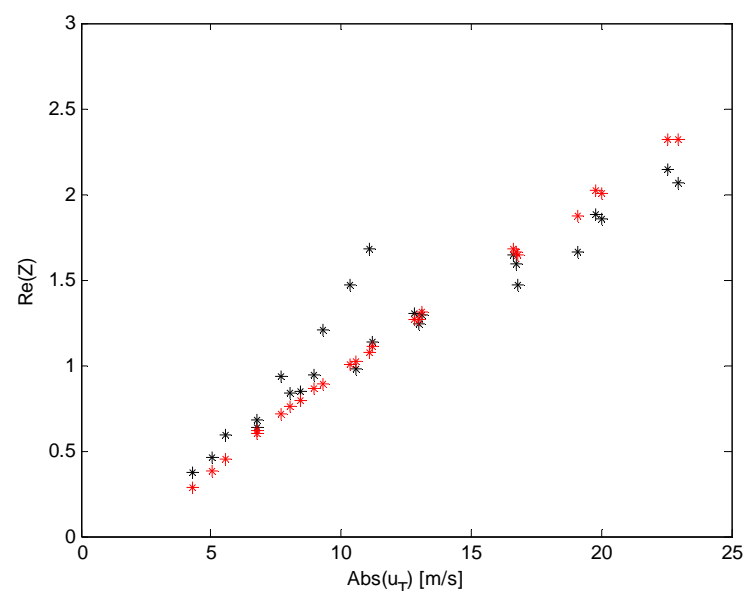

a)

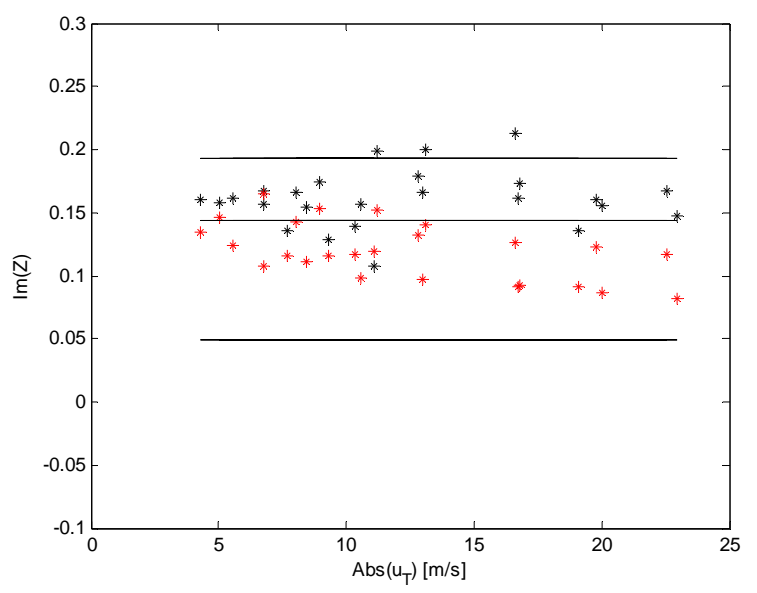

b)

Figure 3. Normalized impedance at $110 \mathrm{~Hz}$ for perforate sample with $3.2 \%$ porosity, for two tone excitation, plotted against summed (total) particle velocity in the holes. The excitation at $110 \mathrm{~Hz}$ is kept constant while the excitation at other frequencies is varied: black - measurement, red - simulation; solid lines - imaginary parts obtained assuming: $l=I_{0}, l=l_{0}+I_{W}$ and $l=2 l_{0}+l_{W}$; a) Real part, b) Imaginary part. 


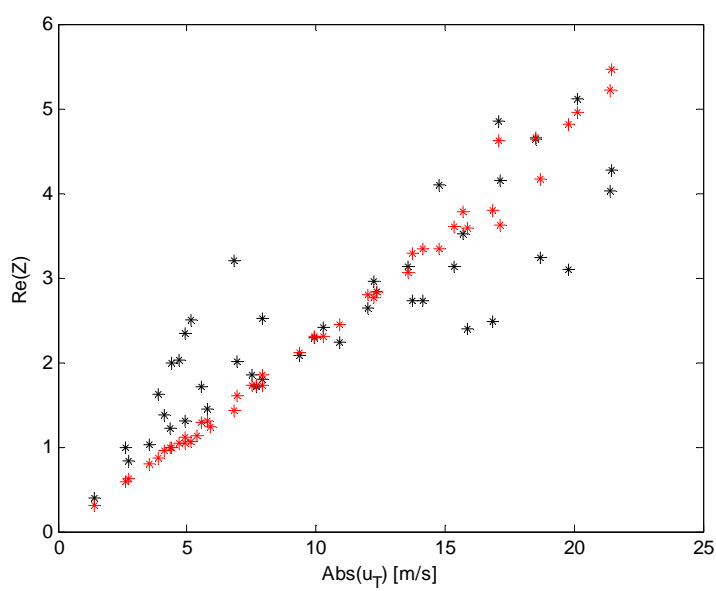

a)

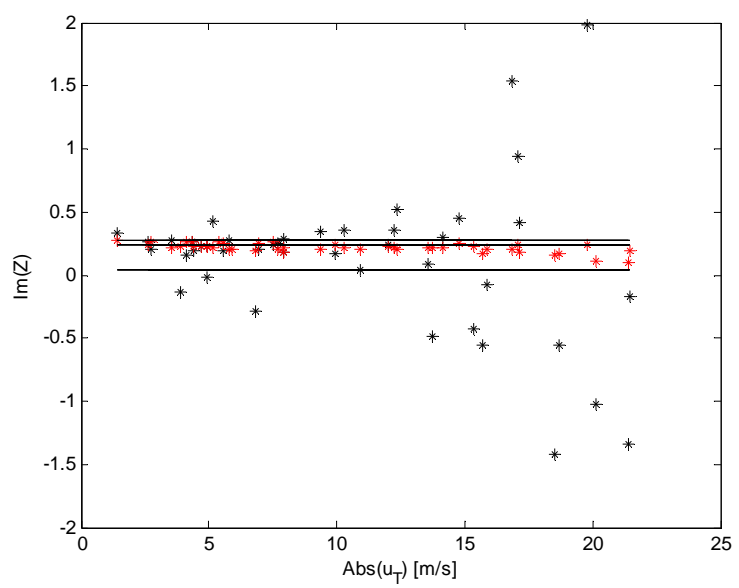

b)

Figure 4. Normalized impedance at $110 \mathrm{~Hz}$ for perforate sample with $2 \%$ porosity, for two tone excitation, plotted against summed (total) particle velocity in the holes. The excitation at $110 \mathrm{~Hz}$ is kept constant while the excitation at other frequencies is varied: black - measurement, red - simulation; solid lines - imaginary parts obtained assuming: $l=I_{0}, l=I_{0}+I_{W}$ and $l=2 l_{0}+l_{W}$; a) Real part, b) Imaginary part.

The results shown in Fig. 3 and Fig. 4 are plotted against the total particle velocity in the holes summed over both frequencies of excitation. This may obviously not be the best quantity to plot against to get a collapse of the data. In Figures 5-8 it is investigated if plotting against the particle velocity at the frequency where the result is evaluated (110 Hz in this case) would be a better candidate. Results are presented for: two tone, three tone, four tone and five tone excitation. It can be seen that even though the voltage supplied to the loudspeaker at $110 \mathrm{~Hz}$ is kept constant the actual level of excitation in terms particle velocity is decreased when the level of excitation at another frequency is increased. This is because the perforate impedance at $110 \mathrm{~Hz}$ increases causing a decrease in particle velocity and an increase in pressure. If the pressure wave amplitude $\left(\mathrm{p}^{+}\right)$incident on the sample is evaluated it is found that this quantity is unchanged. The results show that plotting against particle velocity at $110 \mathrm{~Hz}$ instead of total summed particle velocity gives a better collapse of the resistance results, while the scatter in the reactance results remain more or less the same. 


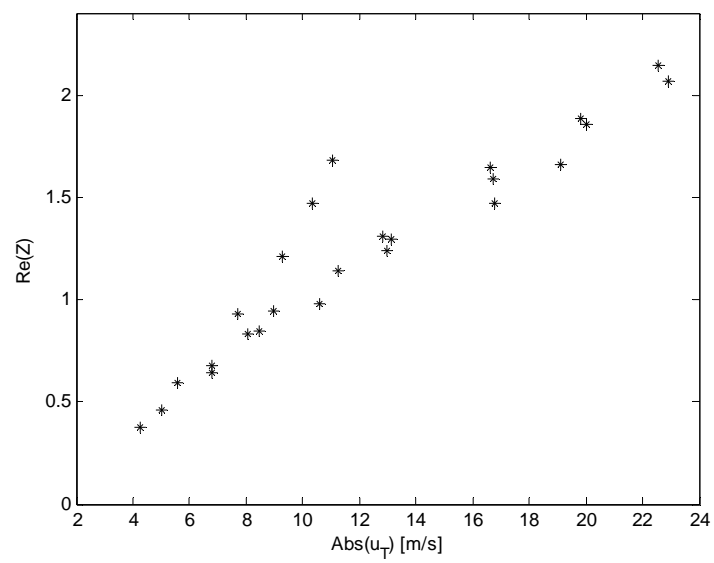

a)

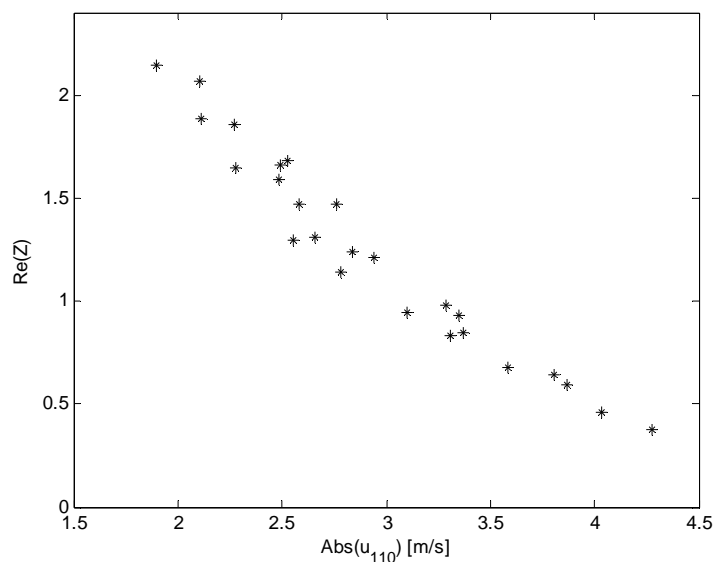

c)

Figure 5. Normalized impedance at $110 \mathrm{~Hz}$ for perforate sample with $3.2 \%$ porosity, for two tone excitation with the level of excitation at $110 \mathrm{~Hz}$ kept constant and excitation at the other frequency varied; solid lines imaginary parts obtained assuming: $l=I_{0}, I=I_{0}+I_{W}$ and $l=2 l_{0}+I_{W}$; a) Real part plotted against total particle velocity, b) Imaginary part plotted against total particle velocity, c) Real part plotted against particle velocity at $110 \mathrm{~Hz}, \mathrm{~d}$ ) Imaginary part plotted against particle velocity at $110 \mathrm{~Hz}$. 


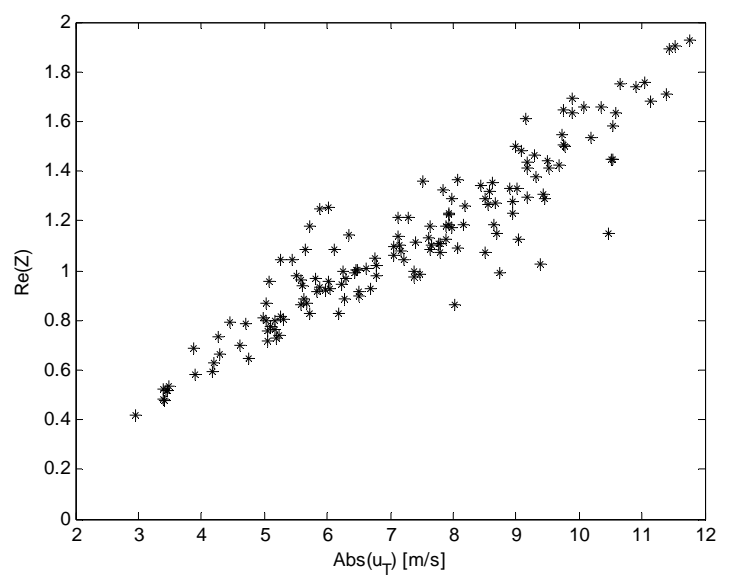

a)

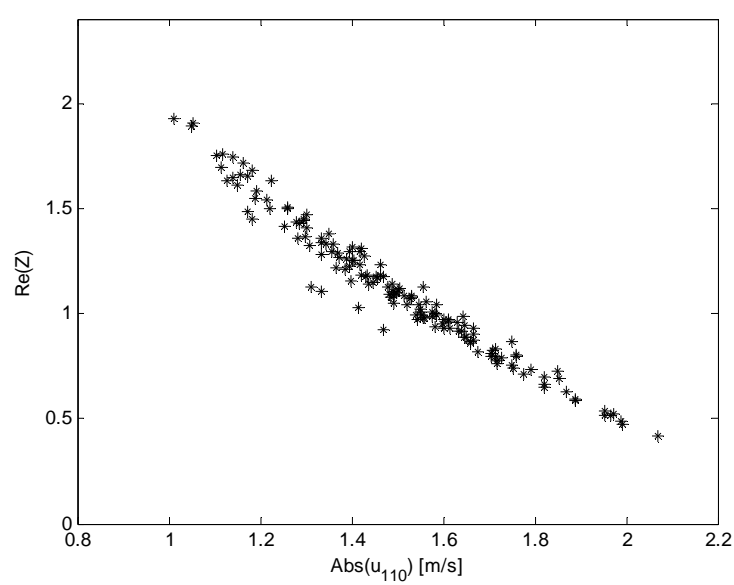

c)

Figure 6. Normalized impedance at $110 \mathrm{~Hz}$ for perforate sample with $3.2 \%$ porosity, for three tone excitation with the level of excitation at $110 \mathrm{~Hz}$ kept constant and excitation at the other frequency varied; solid lines imaginary parts obtained assuming: $I=I_{0}, I=I_{0}+I_{W}$ and $I=2 I_{0}+I_{W}$; a) Real part plotted against total particle velocity, b) Imaginary part plotted against total particle velocity, c) Real part plotted against particle velocity at $110 \mathrm{~Hz}, \mathrm{~d}$ ) Imaginary part plotted against particle velocity at $110 \mathrm{~Hz}$. 


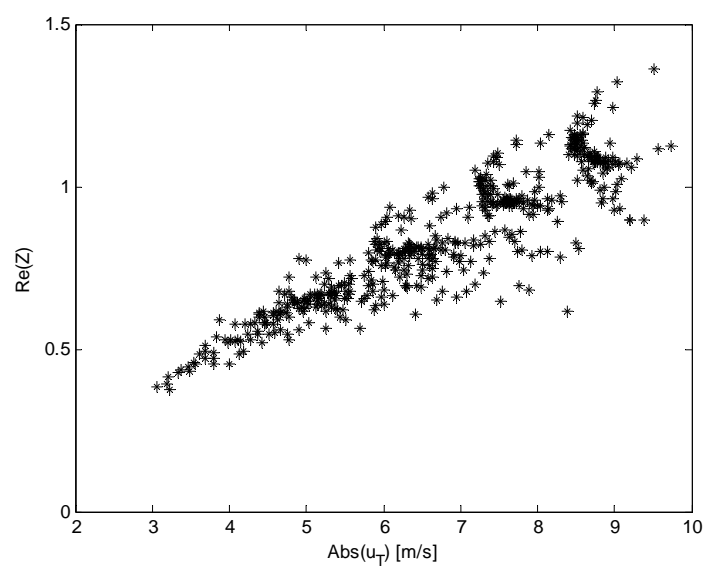

a)

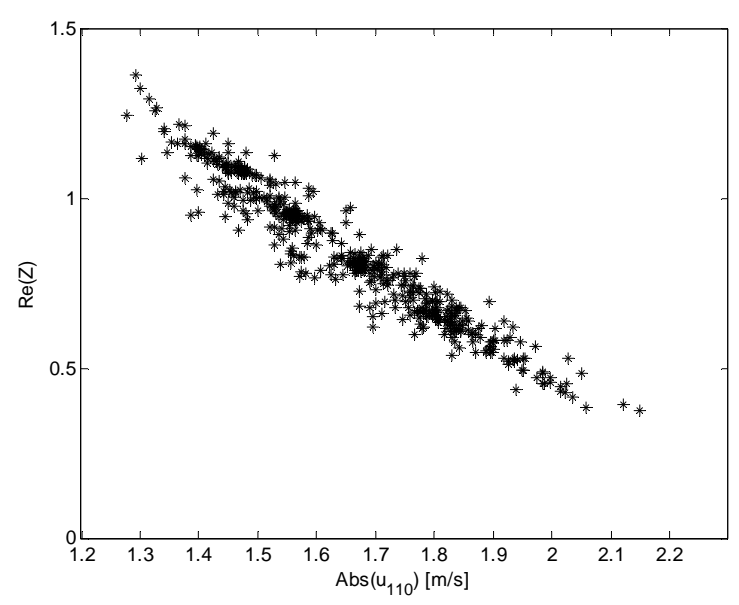

c)

Figure 7. Normalized impedance at $110 \mathrm{~Hz}$ for perforate sample with $3.2 \%$ porosity, for four tone excitation with the level of excitation at $110 \mathrm{~Hz}$ kept constant and excitation at the other frequency varied; solid lines imaginary parts obtained assuming: $I=I_{0}, I=I_{0}+I_{W}$ and $I=2 l_{0}+l_{W}$; a) Real part plotted against total particle velocity, b) Imaginary part plotted against total particle velocity, c) Real part plotted against particle velocity at $110 \mathrm{~Hz}, \mathrm{~d}$ ) Imaginary part plotted against particle velocity at $110 \mathrm{~Hz}$.
8

American Institute of Aeronautics and Astronautics 


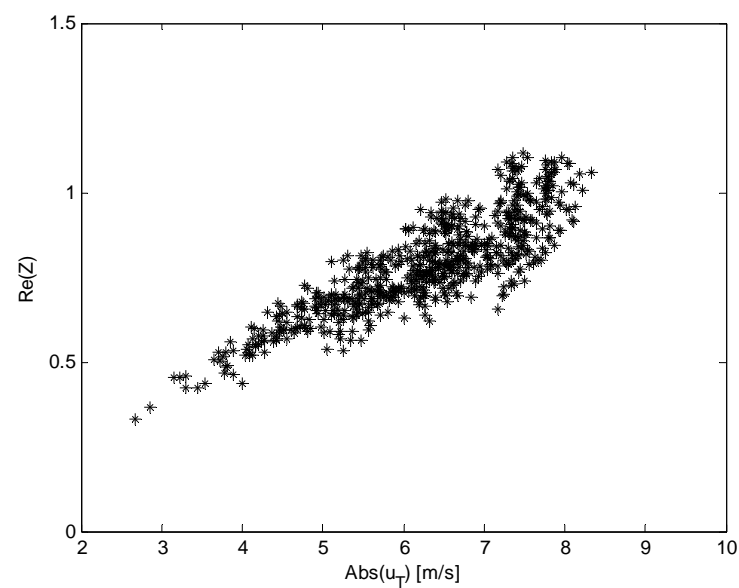

a)

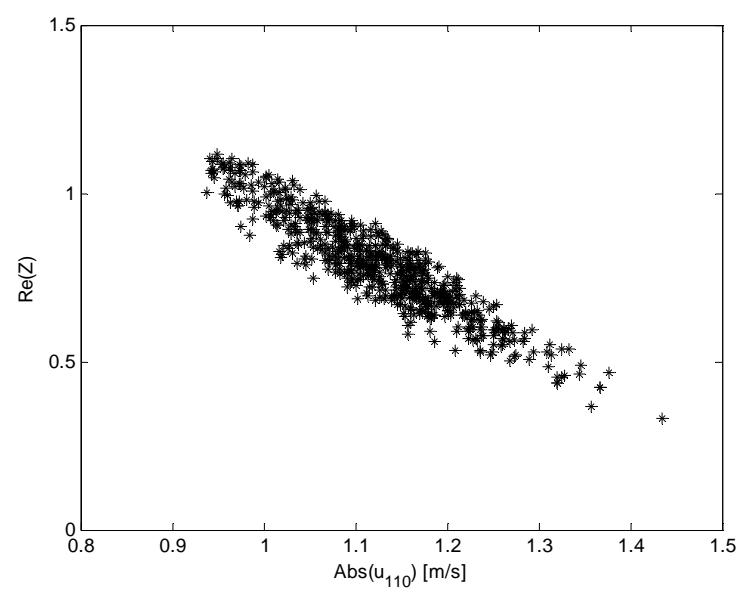

c)

Figure 8. Normalized impedance at $110 \mathrm{~Hz}$ for perforate sample with $3.2 \%$ porosity, for five tone excitation with the level of excitation at $110 \mathrm{~Hz}$ kept constant and excitation at the other frequency varied; solid lines imaginary parts obtained assuming: $I=I_{0}, I=I_{0}+I_{W}$ and $I=2 l_{0}+l_{W}$; a) Real part plotted against total particle velocity, b) Imaginary part plotted against total particle velocity, c) Real part plotted against particle velocity at $110 \mathrm{~Hz}, \mathrm{~d}$ ) Imaginary part plotted against particle velocity at $110 \mathrm{~Hz}$.

\section{Multi tone excitation - effect of combination of frequencies}

It is also of interest to see if the choice of frequency components has an influence on the result. The frequency components used in the present study are: $60 \mathrm{~Hz}, 120 \mathrm{~Hz}, 220 \mathrm{~Hz}, 440 \mathrm{~Hz}$ and $880 \mathrm{~Hz}$. For these frequencies the level of excitation has been varied while the excitation, i.e. the loudspeaker voltage and amplitude of incident pressure wave $\left(p_{+}\right)$, at $110 \mathrm{~Hz}$ remained unchanged. Figures 9 and 10 shows a subset of the two tone excitation results at $110 \mathrm{~Hz}$ where the frequency component varied is indicated. It can be seen that excitation at $120 \mathrm{~Hz}$ which is close to $110 \mathrm{~Hz}$ causes a larger scatter in the results compared to other combinations of frequency components. Even though there is scatter at higher excitation levels also for other combinations of frequencies especially for sample P4 for with smaller porosity. In Figure 11 and 12 results for three tone excitation is shown and again the cases where the level of the $120 \mathrm{~Hz}$ component gives a larger scatter in the result at $110 \mathrm{~Hz}$ compared to other combinations.

Figures 13 to 20 gives corresponding results for three tone excitation for the impedance at: $60 \mathrm{~Hz}, 120 \mathrm{~Hz}, 220$ $\mathrm{Hz}$ and $440 \mathrm{~Hz}$. In these figures the red symbols are used for cases where the level of the frequency component for which the impedance is presented is varied while the levels of excitation at other frequencies are kept constant. The 
black symbols are used for cases where the level of excitation at the frequency studied is instead kept constant while the level at one of the other components is varied. It can be seen that the impedance results when plotted against the particle velocity at the same frequency as where the result is evaluated collapses into two distinct branches, one for the case when the level at the frequency studied is varied and the other for the case that the level at one of the other frequency components is varied. The impedance at $120 \mathrm{~Hz}$, which is close to $110 \mathrm{~Hz}$, again behaves in a different way and can have negative resistance values and very large reactance values.

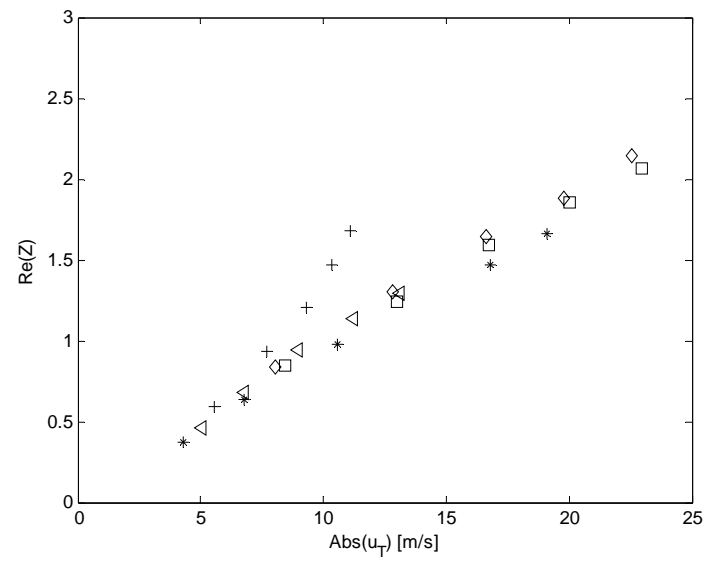

a)

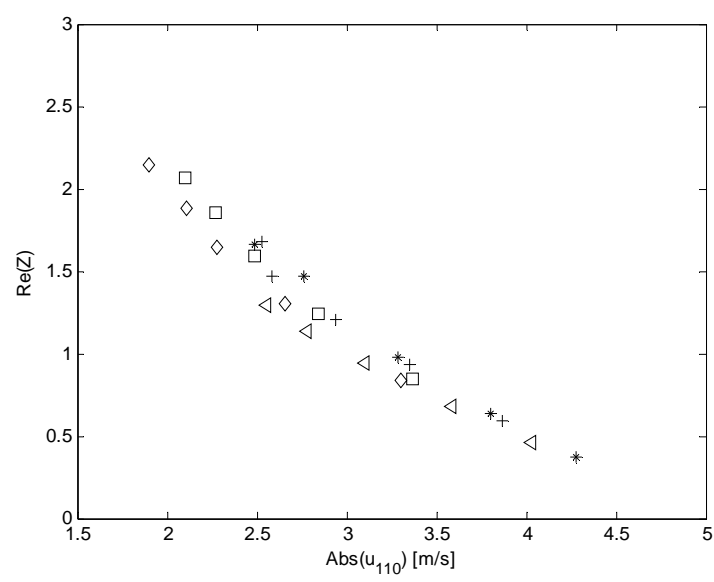

c)

Figure 9. Normalized impedance at $110 \mathrm{~Hz}$ for perforate sample with $3.2 \%$ porosity, for two tone excitation with the level of excitation at $110 \mathrm{~Hz}$ kept constant and excitation at the other frequency varied: black measurement, red - simulation; stars $-60 \mathrm{~Hz}$, plus - $120 \mathrm{~Hz}$, squares - $220 \mathrm{~Hz}$, diamonds - $440 \mathrm{~Hz}$, triangles $-880 \mathrm{~Hz}$; solid lines - imaginary parts obtained assuming: $l=I_{0}, I=I_{0}+I_{W}$ and $l=2 l_{0}+l_{W}$; a) Real part plotted against summed particle velocity, b) Imaginary part plotted against summed particle velocity, c) Real part plotted against particle velocity at $110 \mathrm{~Hz}$, d) Imaginary part plotted against particle velocity at $110 \mathrm{~Hz}$. 


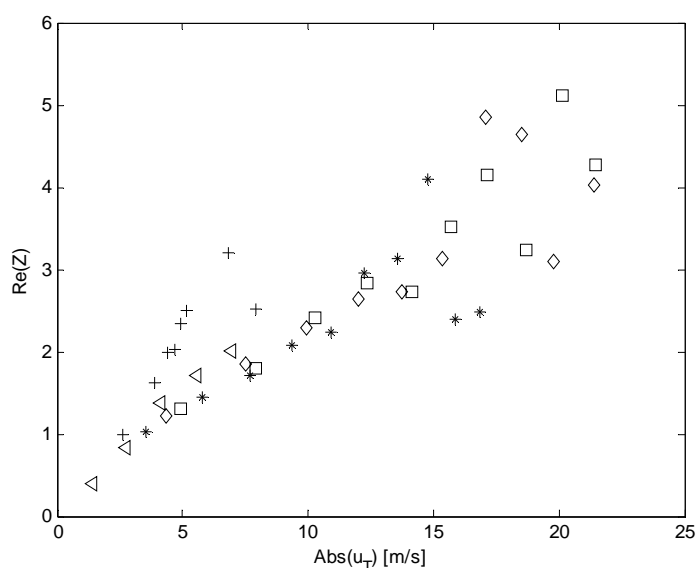

a)

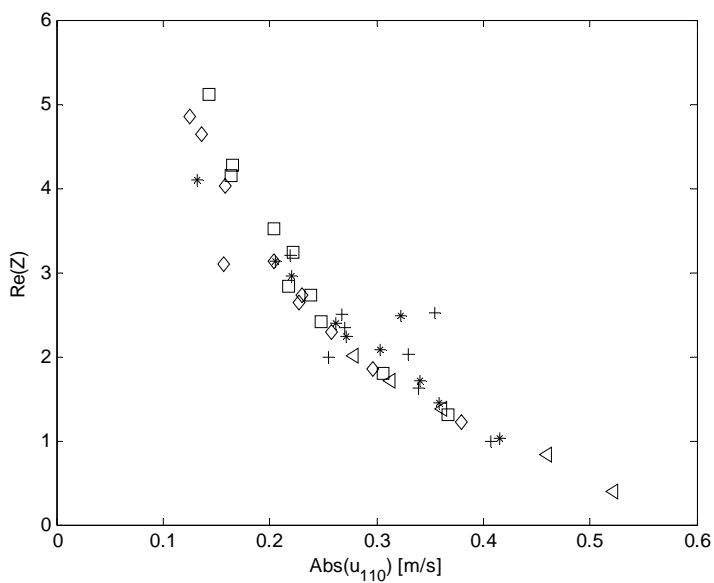

c)

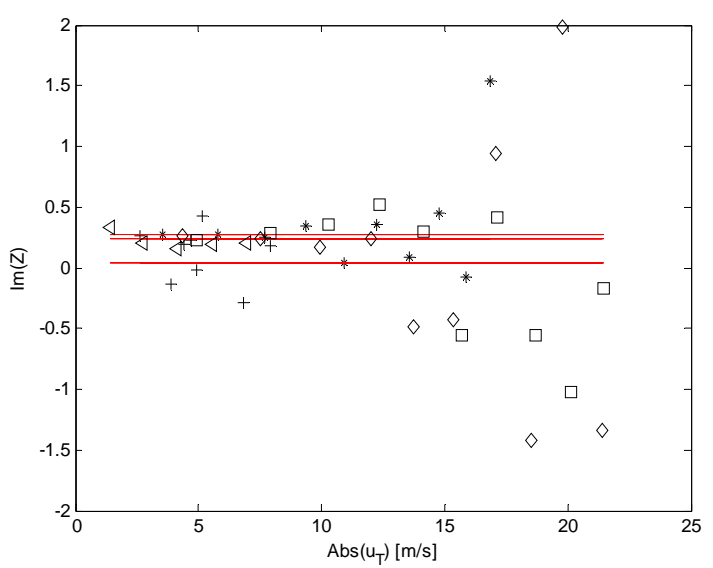

b)

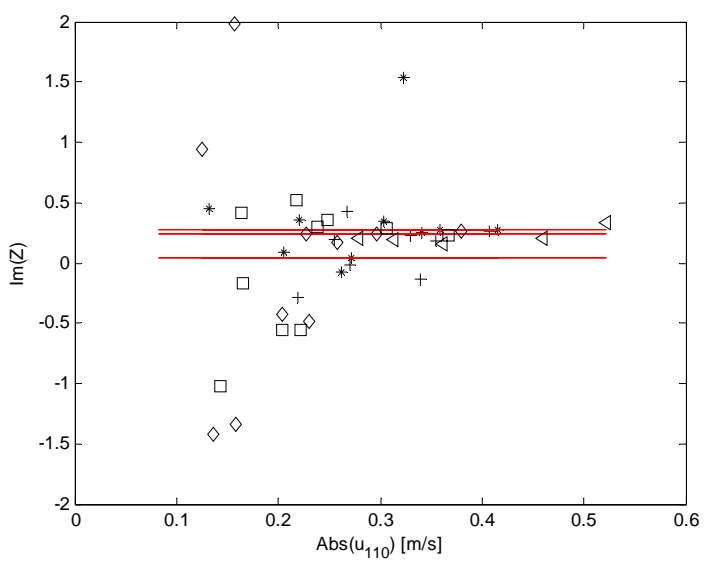

d)

Figure 10. Normalized impedance at $110 \mathrm{~Hz}$ for perforate sample with $2 \%$ porosity, for two tone excitation with the level of excitation at $110 \mathrm{~Hz}$ kept constant and excitation at the other frequency varied: black measurement, red - simulation; stars - $60 \mathrm{~Hz}$, plus - $120 \mathrm{~Hz}$, squares - $220 \mathrm{~Hz}$, diamonds - $440 \mathrm{~Hz}$, triangles $-880 \mathrm{~Hz}$; solid lines - imaginary parts obtained assuming: $l=l_{0}, l=l_{0}+l_{W}$ and $l=2 l_{0}+l_{W}$; a) Real part plotted against summed particle velocity, b) Imaginary part plotted against summed particle velocity, c) Real part plotted against particle velocity at $110 \mathrm{~Hz}$, d) Imaginary part plotted against particle velocity at $110 \mathrm{~Hz}$. 


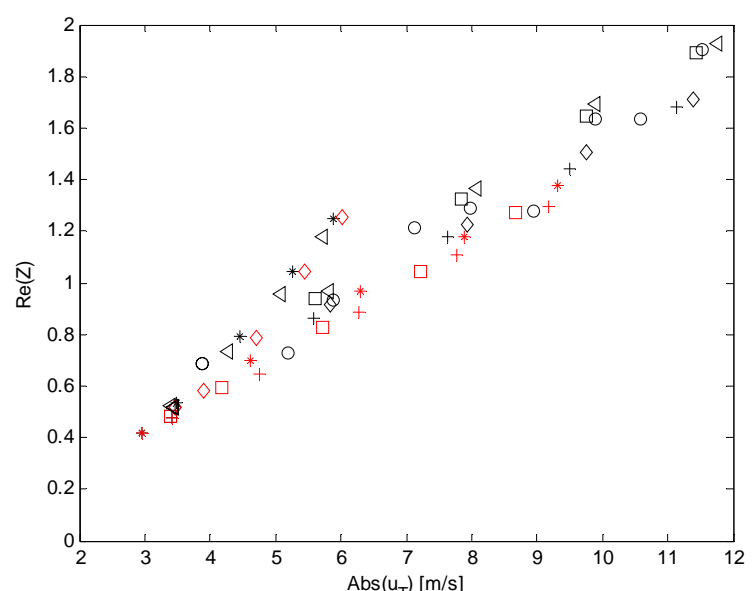

a)

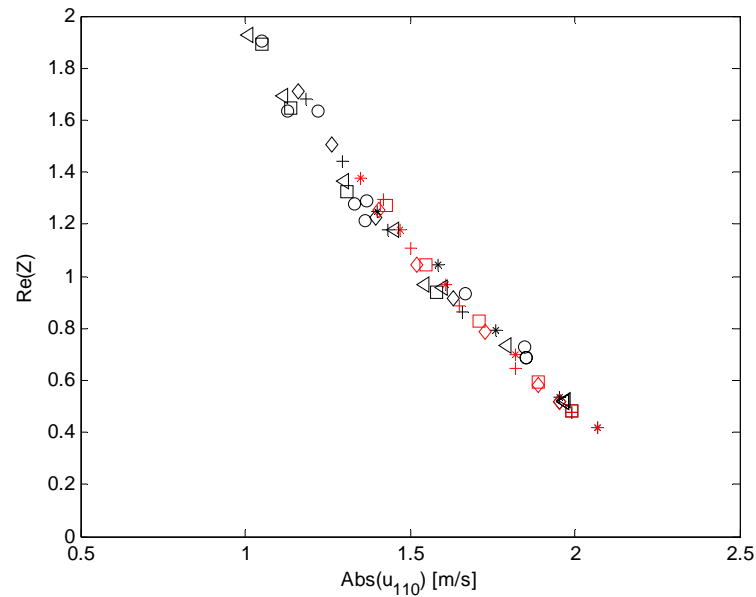

c)

Figure 11. Normalized impedance at $110 \mathrm{~Hz}$ for perforate sample with $3.2 \%$ porosity, for three tone excitation with the level of excitation at $110 \mathrm{~Hz}$ kept constant and excitation at other frequencies varied, frequencies:

black stars - variation at $120 \mathrm{~Hz}, 60 \mathrm{~Hz}$ kept constant, red stars - variation at $60 \mathrm{~Hz}, 120 \mathrm{~Hz}$ kept constant, black plus - variation at $220 \mathrm{~Hz}, 60 \mathrm{~Hz}$ kept constant, red plus - variation at $60 \mathrm{~Hz}, 220 \mathrm{~Hz}$ kept constant, black squares - variation at $440 \mathrm{~Hz}, 60 \mathrm{~Hz}$ kept constant, red squares - variation at $60 \mathrm{~Hz}, 440 \mathrm{~Hz} \mathrm{kept}$ constant,

black diamonds - variation at $220 \mathrm{~Hz}, 120 \mathrm{~Hz}$ kept constant, red diamonds - variation at $120 \mathrm{~Hz}, 220 \mathrm{~Hz}$ kept constant,

black triangles - variation at $440 \mathrm{~Hz}, 120 \mathrm{~Hz}$ kept constant, red triangles - variation at $120 \mathrm{~Hz}, 440 \mathrm{~Hz}$ kept constant,

black rings - variation at $440 \mathrm{~Hz}, 220 \mathrm{~Hz}$ kept constant ,red rings - variation at $220 \mathrm{~Hz}, 440 \mathrm{~Hz}$ kept constant ; solid lines - imaginary parts obtained assuming: $l=I_{0}, I=I_{0}+I_{W}$ and $I=2 I_{0}+l_{W}$;

a) Real part plotted against particle total velocity, b) Imaginary part plotted against total velocity,

c) Real part plotted against velocity at $110 \mathrm{~Hz}$, d) Imaginary part plotted against velocity at $110 \mathrm{~Hz}$. 


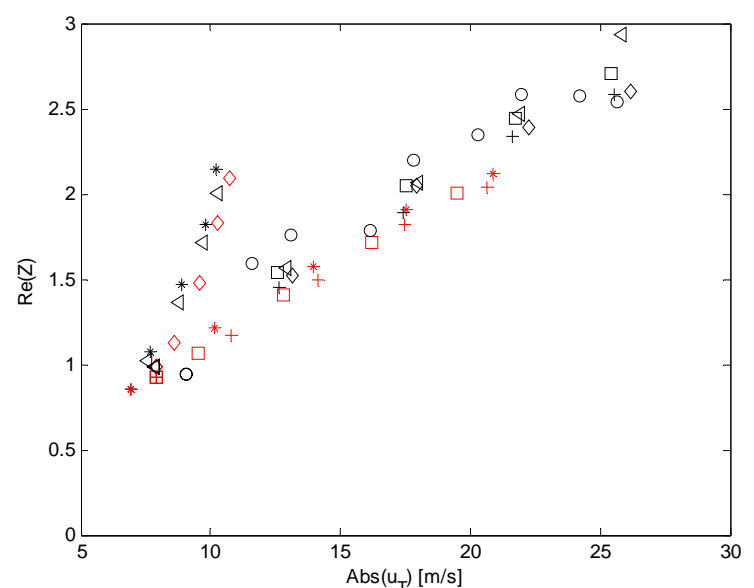

a)

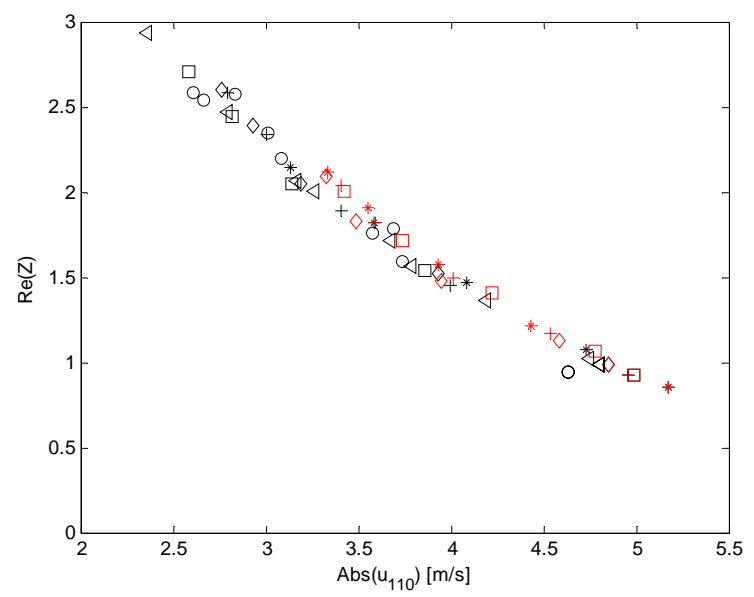

c)

Figure 12. Normalized impedance at $110 \mathrm{~Hz}$ for perforate sample with $2 \%$ porosity, for three tone excitation with the level of excitation at $110 \mathrm{~Hz}$ kept constant and excitation at other frequencies varied, frequencies: black stars - variation at $120 \mathrm{~Hz}, 60 \mathrm{~Hz}$ kept constant, red stars - variation at $60 \mathrm{~Hz}, 120 \mathrm{~Hz}$ kept constant, black plus - variation at $220 \mathrm{~Hz}, 60 \mathrm{~Hz}$ kept constant, red plus - variation at $60 \mathrm{~Hz}, 220 \mathrm{~Hz}$ kept constant, black squares - variation at $440 \mathrm{~Hz}, 60 \mathrm{~Hz}$ kept constant, red squares - variation at $60 \mathrm{~Hz}, 440 \mathrm{~Hz} \mathrm{kept}$ constant,

black diamonds - variation at $220 \mathrm{~Hz}, 120 \mathrm{~Hz}$ kept constant, red diamonds - variation at $120 \mathrm{~Hz}, 220 \mathrm{~Hz}$ kept constant,

black triangles - variation at $440 \mathrm{~Hz}, 120 \mathrm{~Hz}$ kept constant, red triangles - variation at $120 \mathrm{~Hz}, 440 \mathrm{~Hz}$ kept constant,

black rings - variation at $440 \mathrm{~Hz}, 220 \mathrm{~Hz}$ kept constant ,red rings - variation at $220 \mathrm{~Hz}, 440 \mathrm{~Hz}$ kept constant ; solid lines - imaginary parts obtained assuming: $l=l_{0}, l=l_{0}+l_{W}$ and $l=2 l_{0}+l_{W}$;

a) Real part plotted against particle total velocity, b) Imaginary part plotted against total velocity,

c) Real part plotted against velocity at $110 \mathrm{~Hz}$, d) Imaginary part plotted against velocity at $110 \mathrm{~Hz}$. 


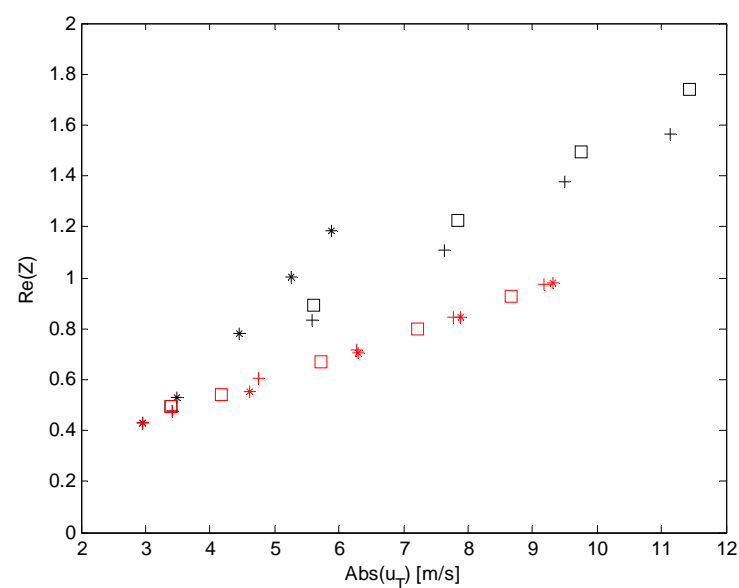

a)

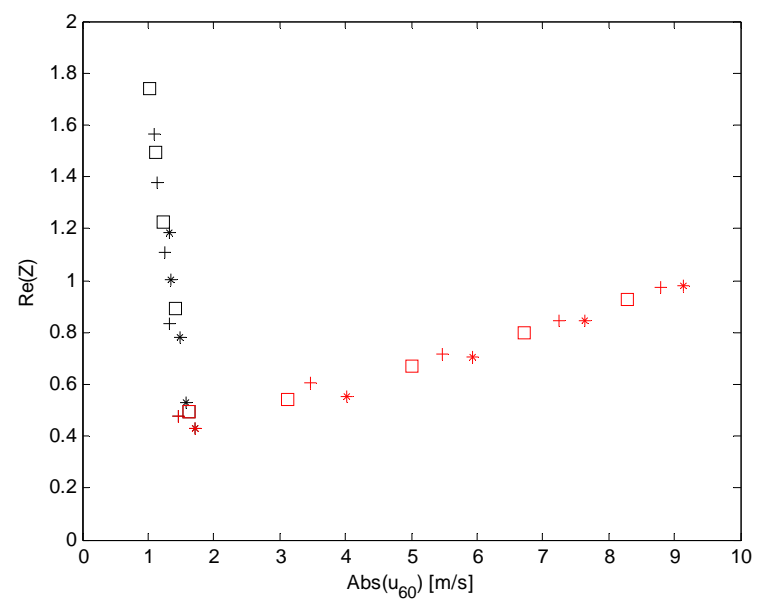

c)

Figure 13. Normalized impedance at $60 \mathrm{~Hz}$ for perforate sample with $3.2 \%$ porosity, for three tone excitation with the level of excitation at $110 \mathrm{~Hz}$ kept constant and excitation at other frequencies varied, frequencies: black stars - variation at $120 \mathrm{~Hz}, 60 \mathrm{~Hz}$ kept constant, red stars - variation at $60 \mathrm{~Hz}, 120 \mathrm{~Hz}$ kept constant, black plus - variation at $220 \mathrm{~Hz}, 60 \mathrm{~Hz}$ kept constant, red plus - variation at $60 \mathrm{~Hz}, 220 \mathrm{~Hz}$ kept constant, black squares - variation at $440 \mathrm{~Hz}, 60 \mathrm{~Hz}$ kept constant, red squares - variation at $60 \mathrm{~Hz}, 440 \mathrm{~Hz} \mathrm{kept}$ constant;

solid lines - imaginary parts obtained assuming: $I=I_{0}, I=I_{0}+I_{W}$ and $I=2 l_{0}+I_{W}$;

a) Real part plotted against particle total velocity, b) Imaginary part plotted against total velocity,

c) Real part plotted against velocity at $60 \mathrm{~Hz}$, d) Imaginary part plotted against velocity at $60 \mathrm{~Hz}$. 


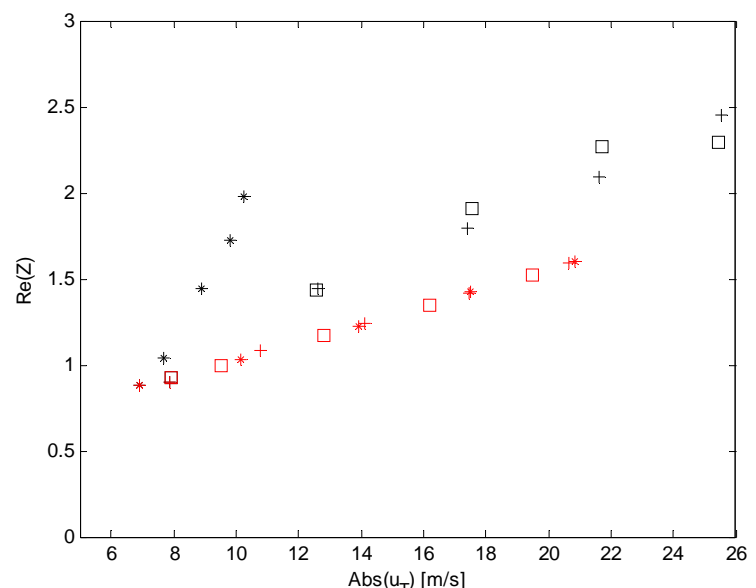

a)

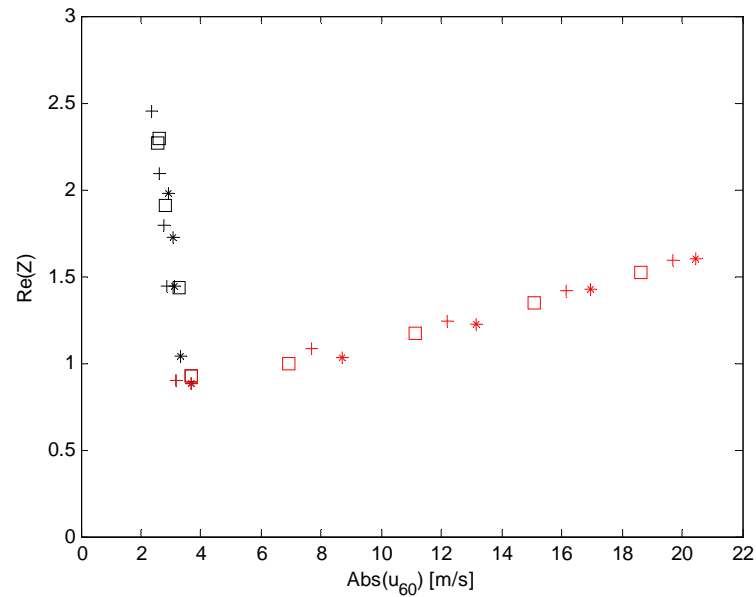

c)

Figure 14. Normalized impedance at $60 \mathrm{~Hz}$ for perforate sample with $2 \%$ porosity, for three tone excitation with the level of excitation at $110 \mathrm{~Hz}$ kept constant and excitation at other frequencies varied, frequencies: black stars - variation at $120 \mathrm{~Hz}, 60 \mathrm{~Hz}$ kept constant, red stars - variation at $60 \mathrm{~Hz}, 120 \mathrm{~Hz}$ kept constant, black plus - variation at $220 \mathrm{~Hz}, 60 \mathrm{~Hz}$ kept constant, red plus - variation at $60 \mathrm{~Hz}, 220 \mathrm{~Hz}$ kept constant, black squares - variation at $440 \mathrm{~Hz}, 60 \mathrm{~Hz}$ kept constant, red squares - variation at $60 \mathrm{~Hz}, 440 \mathrm{~Hz} \mathrm{kept}$ constant;

solid lines - imaginary parts obtained assuming: $I=I_{0}, I=I_{0}+I_{W}$ and $I=2 l_{0}+l_{W}$;

a) Real part plotted against particle total velocity, b) Imaginary part plotted against total velocity, c) Real part plotted against velocity at $60 \mathrm{~Hz}$, d) Imaginary part plotted against velocity at $60 \mathrm{~Hz}$. 


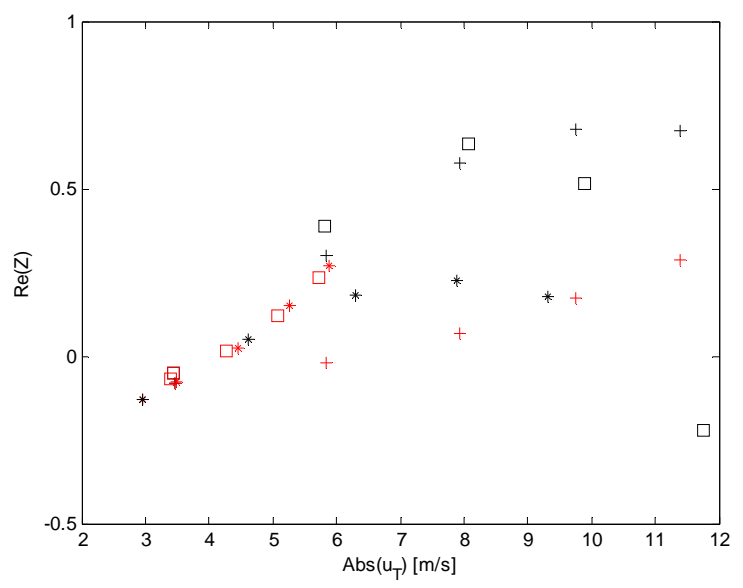

a)

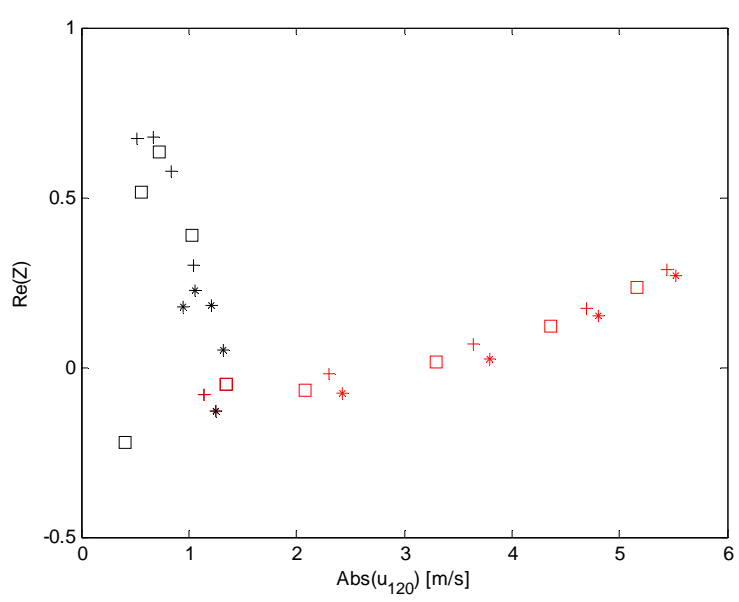

c)

Figure 15. Normalized impedance at $120 \mathrm{~Hz}$ for perforate sample with $3.2 \%$ porosity, for three tone excitation with the level of excitation at $110 \mathrm{~Hz}$ kept constant and excitation at other frequencies varied, frequencies:

black stars - variation at $60 \mathrm{~Hz}, 120 \mathrm{~Hz}$ kept constant, red stars - variation at $120 \mathrm{~Hz}, 60 \mathrm{~Hz}$ kept constant, black plus - variation at $220 \mathrm{~Hz}, 120 \mathrm{~Hz}$ kept constant, red plus - variation at $120 \mathrm{~Hz}, 220 \mathrm{~Hz}$ kept constant, black squares - variation at $440 \mathrm{~Hz}, 120 \mathrm{~Hz}$ kept constant, red squares - variation at $120 \mathrm{~Hz}, 440 \mathrm{~Hz} \mathrm{kept}$ constant;

solid lines - imaginary parts obtained assuming: $I=I_{0}, I=I_{0}+I_{W}$ and $l=2 l_{0}+I_{W}$;

a) Real part plotted against particle total velocity, b) Imaginary part plotted against total velocity, c) Real part plotted against velocity at $120 \mathrm{~Hz}$, d) Imaginary part plotted against velocity at $120 \mathrm{~Hz}$. 


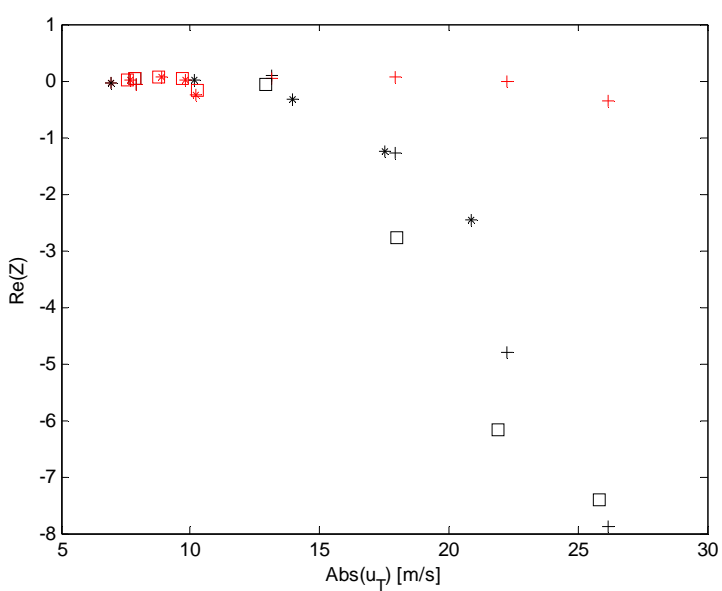

a)

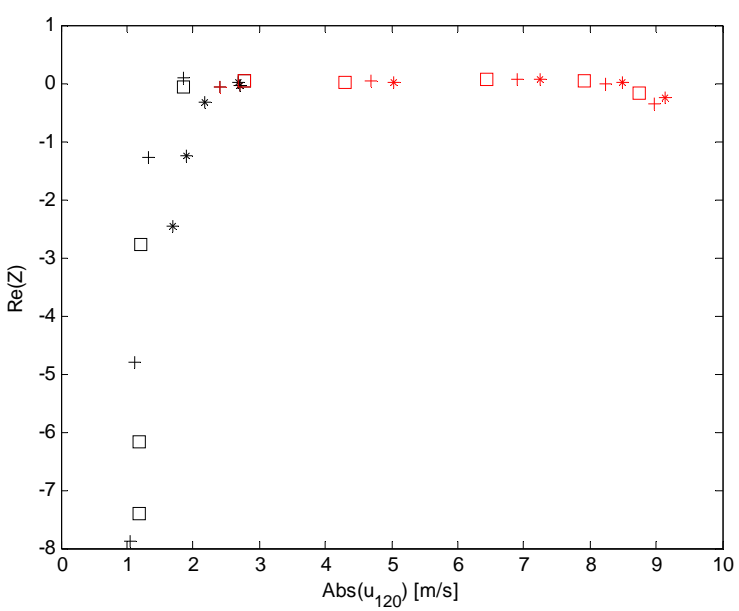

c)

Figure 16. Normalized impedance at $120 \mathrm{~Hz}$ for perforate sample with $2 \%$ porosity, for three tone excitation with the level of excitation at $110 \mathrm{~Hz}$ kept constant and excitation at other frequencies varied, frequencies: black stars - variation at $60 \mathrm{~Hz}, 120 \mathrm{~Hz}$ kept constant, red stars - variation at $120 \mathrm{~Hz}, 60 \mathrm{~Hz}$ kept constant, black plus - variation at $220 \mathrm{~Hz}, 120 \mathrm{~Hz}$ kept constant, red plus - variation at $120 \mathrm{~Hz}, 220 \mathrm{~Hz}$ kept constant, black squares - variation at $440 \mathrm{~Hz}, 120 \mathrm{~Hz}$ kept constant, red squares - variation at $120 \mathrm{~Hz}, 440 \mathrm{~Hz} \mathrm{kept}$ constant;

solid lines - imaginary parts obtained assuming: $I=I_{0}, I=I_{0}+I_{W}$ and $l=2 l_{0}+l_{W}$;

a) Real part plotted against particle total velocity, b) Imaginary part plotted against total velocity,

c) Real part plotted against velocity at $120 \mathrm{~Hz}$, d) Imaginary part plotted against velocity at $120 \mathrm{~Hz}$. 


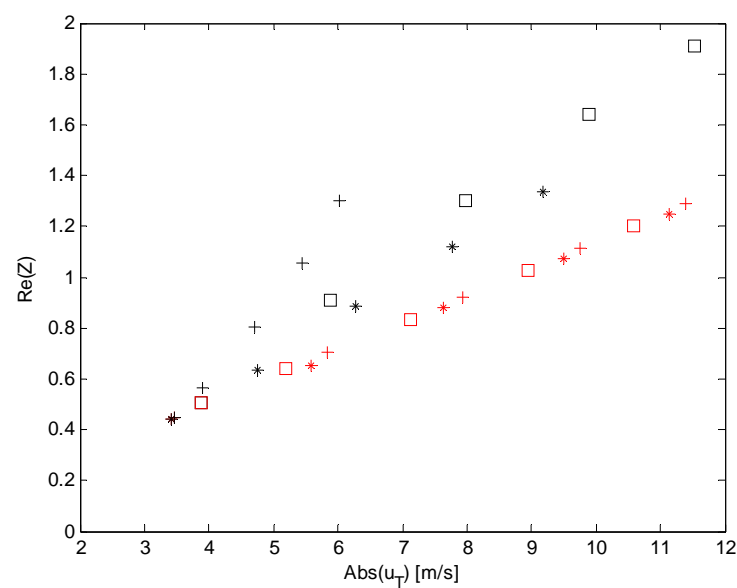

a)

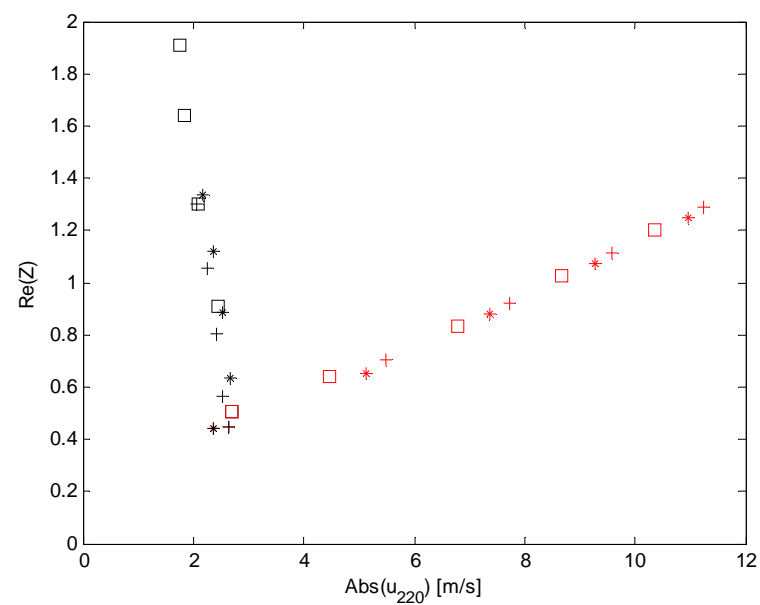

c)

Figure 17. Normalized impedance at $220 \mathrm{~Hz}$ for perforate sample with $3.2 \%$ porosity, for three tone excitation with the level of excitation at $110 \mathrm{~Hz}$ kept constant and excitation at other frequencies varied, frequencies:

black stars - variation at $60 \mathrm{~Hz}, 220 \mathrm{~Hz}$ kept constant, red stars - variation at $220 \mathrm{~Hz}, 60 \mathrm{~Hz}$ kept constant, black plus - variation at $120 \mathrm{~Hz}, 220 \mathrm{~Hz}$ kept constant, red plus - variation at $220 \mathrm{~Hz}, 120 \mathrm{~Hz}$ kept constant, black squares - variation at $440 \mathrm{~Hz}, 220 \mathrm{~Hz}$ kept constant, red squares - variation at $220 \mathrm{~Hz}, 440 \mathrm{~Hz} \mathrm{kept}$ constant;

solid lines - imaginary parts obtained assuming: $I=I_{0}, I=I_{0}+I_{W}$ and $I=2 l_{0}+I_{W}$;

a) Real part plotted against particle total velocity, b) Imaginary part plotted against total velocity,

c) Real part plotted against velocity at $220 \mathrm{~Hz}$, d) Imaginary part plotted against velocity at $220 \mathrm{~Hz}$. 


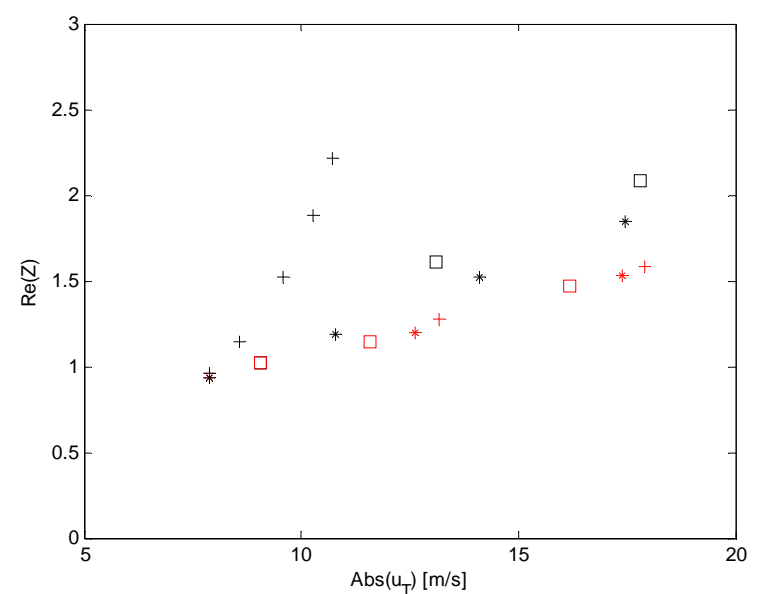

a)

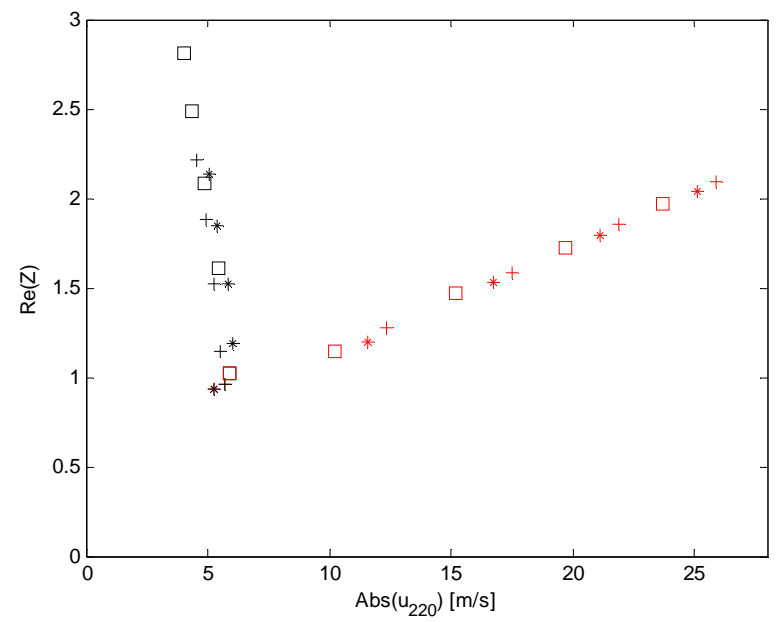

c)

Figure 18. Normalized impedance at $220 \mathrm{~Hz}$ for perforate sample with $2 \%$ porosity, for three tone excitation with the level of excitation at $110 \mathrm{~Hz}$ kept constant and excitation at other frequencies varied, frequencies: black stars - variation at $60 \mathrm{~Hz}, 220 \mathrm{~Hz}$ kept constant, red stars - variation at $220 \mathrm{~Hz}, 60 \mathrm{~Hz}$ kept constant, black plus - variation at $120 \mathrm{~Hz}, 220 \mathrm{~Hz}$ kept constant, red plus - variation at $220 \mathrm{~Hz}, 120 \mathrm{~Hz}$ kept constant, black squares - variation at $440 \mathrm{~Hz}, 220 \mathrm{~Hz}$ kept constant, red squares - variation at $220 \mathrm{~Hz}, 440 \mathrm{~Hz} \mathrm{kept}$ constant;

solid lines - imaginary parts obtained assuming: $I=I_{0}, I=I_{0}+I_{W}$ and $I=2 l_{0}+I_{W}$;

a) Real part plotted against particle total velocity, b) Imaginary part plotted against total velocity,

c) Real part plotted against velocity at $220 \mathrm{~Hz}$, d) Imaginary part plotted against velocity at $220 \mathrm{~Hz}$. 


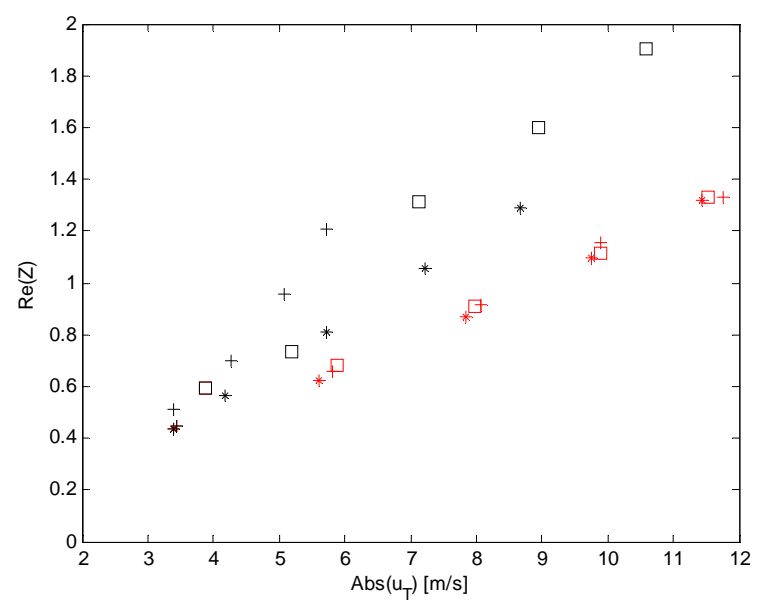

a)

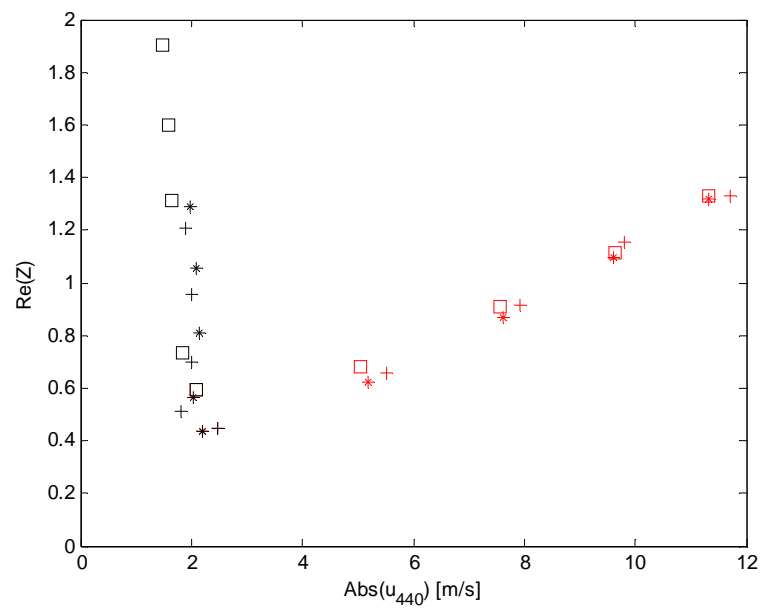

c)

Figure 19. Normalized impedance at $440 \mathrm{~Hz}$ for perforate sample with $3.2 \%$ porosity, for three tone excitation with the level of excitation at $110 \mathrm{~Hz}$ kept constant and excitation at other frequencies varied, frequencies:

black stars - variation at $60 \mathrm{~Hz}, 440 \mathrm{~Hz}$ kept constant, red stars - variation at $440 \mathrm{~Hz}, 60 \mathrm{~Hz}$ kept constant, black plus - variation at $120 \mathrm{~Hz}, 440 \mathrm{~Hz}$ kept constant, red plus - variation at $440 \mathrm{~Hz}, 120 \mathrm{~Hz}$ kept constant, black squares - variation at $220 \mathrm{~Hz}, 440 \mathrm{~Hz}$ kept constant, red squares - variation at $440 \mathrm{~Hz}, 220 \mathrm{~Hz} \mathrm{kept}$ constant;

solid lines - imaginary parts obtained assuming: $I=I_{0}, I=I_{0}+I_{W}$ and $l=2 l_{0}+l_{W}$;

a) Real part plotted against particle total velocity, b) Imaginary part plotted against total velocity, c) Real part plotted against velocity at $440 \mathrm{~Hz}$, d) Imaginary part plotted against velocity at $440 \mathrm{~Hz}$. 


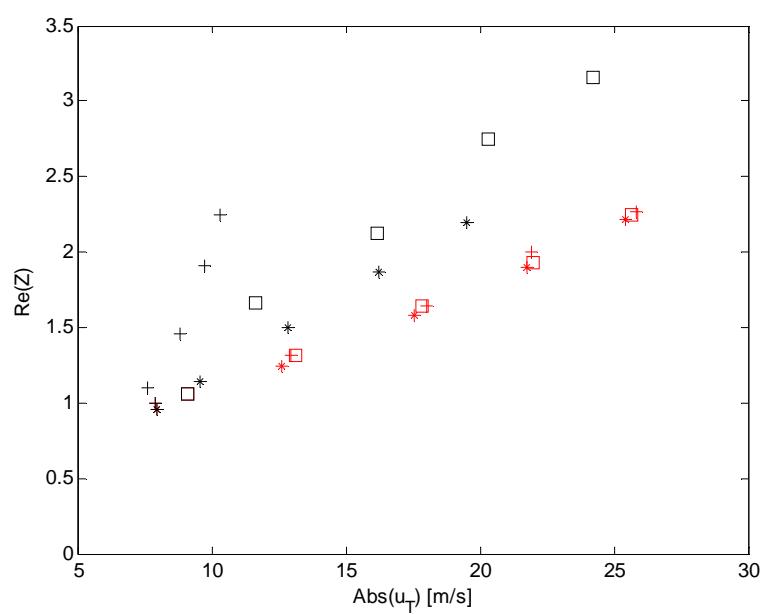

a)

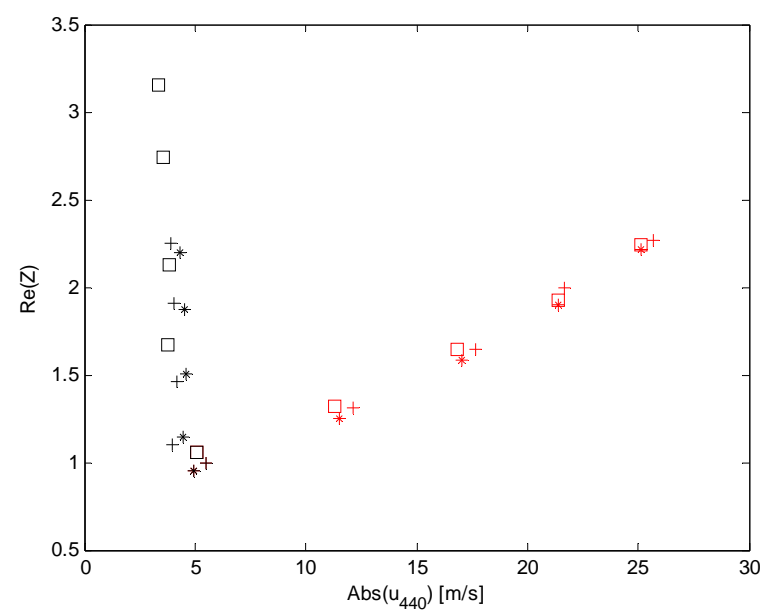

c)

Figure 20. Normalized impedance at $440 \mathrm{~Hz}$ for perforate sample with $2 \%$ porosity, for three tone excitation with the level of excitation at $110 \mathrm{~Hz}$ kept constant and excitation at other frequencies varied, frequencies: black stars - variation at $60 \mathrm{~Hz}, 440 \mathrm{~Hz}$ kept constant, red stars - variation at $440 \mathrm{~Hz}, 60 \mathrm{~Hz}$ kept constant, black plus - variation at $120 \mathrm{~Hz}, 440 \mathrm{~Hz}$ kept constant, red plus - variation at $440 \mathrm{~Hz}, 120 \mathrm{~Hz}$ kept constant, black squares - variation at $220 \mathrm{~Hz}, 440 \mathrm{~Hz}$ kept constant, red squares - variation at $440 \mathrm{~Hz}, 220 \mathrm{~Hz} \mathrm{kept}$ constant;

solid lines - imaginary parts obtained assuming: $I=I_{0}, I=I_{0}+I_{W}$ and $I=2 l_{0}+I_{W}$;

a) Real part plotted against particle total velocity, b) Imaginary part plotted against total velocity,

c) Real part plotted against velocity at $440 \mathrm{~Hz}$, d) Imaginary part plotted against velocity at $440 \mathrm{~Hz}$.

\section{Multi tone excitation - effect of phase}

In order to test if changing the phase of the higher harmonics has an influence on the result a standard impedance tube tests was made with excitation at $110 \mathrm{~Hz}$ and $330 \mathrm{~Hz} \mathrm{in}^{18}$. The level of excitation was varied either by changing the excitation level at $110 \mathrm{~Hz}$ or $330 \mathrm{~Hz}$. At each excitation level the phase at $330 \mathrm{~Hz}$ was shifted 180 degrees. Figures 21 and 22 show comparisons of experimental results and simulation results. In Fig. 21 the normalized impedance at $330 \mathrm{~Hz}$ obtained when the level of excitation at $110 \mathrm{~Hz}$ was varied is show for cases where the phase at $330 \mathrm{~Hz}$ is varied. In the measurements the phase was shifted by 180 degrees while a few additional results are 
shown in the simulation results. Figure 22 shows the corresponding results at $110 \mathrm{~Hz}$. When comparing the experimental and simulated results it should be noticed that the reference case shown as solid lines do not have exactly the same phase in the experiments and simulations. What should be compared is the magnitude of the difference caused by a phase shift. It can be seen that this variation is predicted well by the simulation. The phase relation between the tones is of importance at least at higher ratios between the velocities.
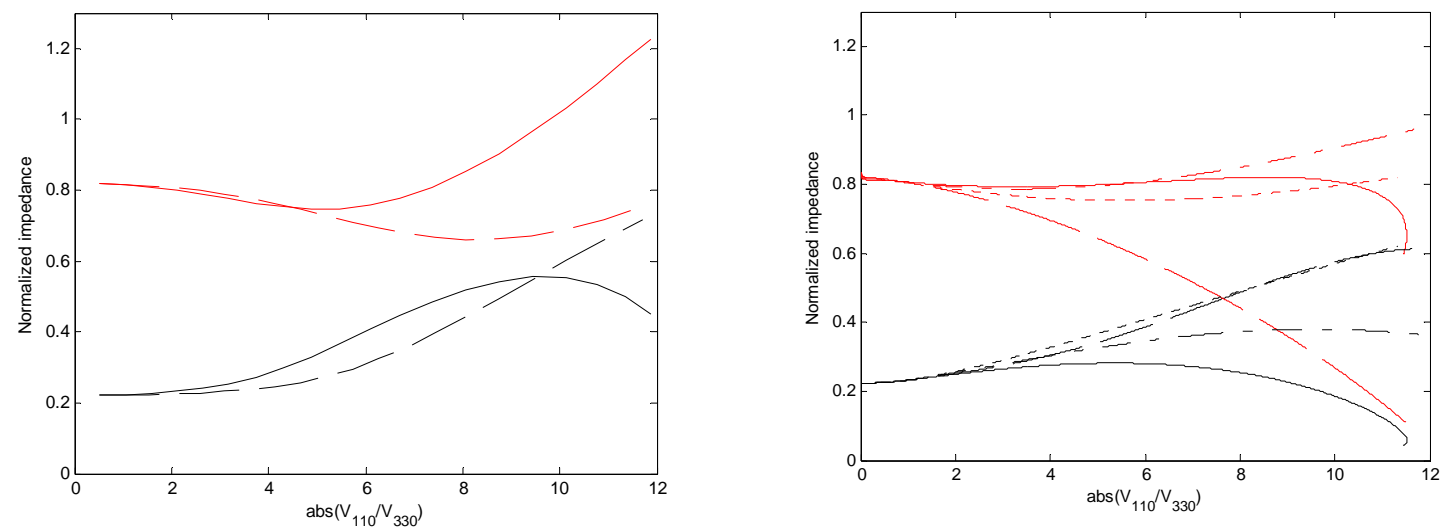

Figure 21. Real and imaginary parts of normalised impedance at $330 \mathrm{~Hz}$ for a perforate sample with $2 \%$ porosity plotted against velocity ratio for excitation at $110 \mathrm{~Hz}$ varied and excitation at $330 \mathrm{~Hz}$ kept constant, from $^{18}$ : black - real part, red - imaginary part, solid line - phase at $330 \mathrm{~Hz}$ not shifted, dashed - phase at 330 Hz shifted 180 degrees, dashed-dotted - phase at $330 \mathrm{~Hz}$ shifted 60 degrees, dotted - phase at $330 \mathrm{~Hz}$ shifted 90 degrees. a) Measured, b) simulation.
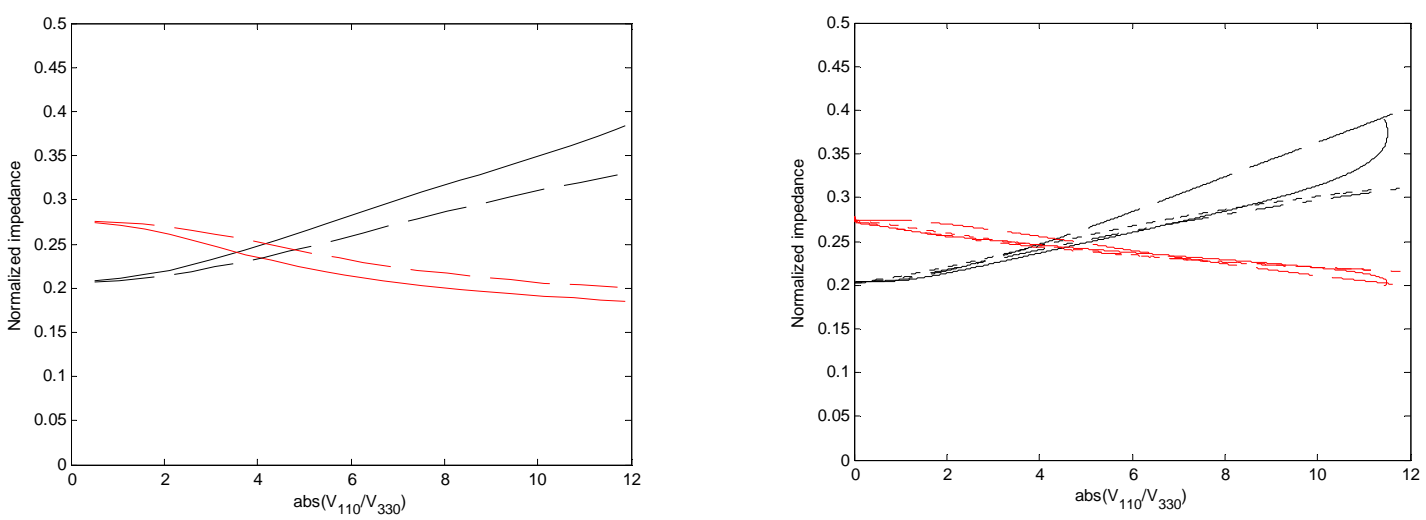

Figure 22. Real and imaginary parts of normalised impedance at $110 \mathrm{~Hz}$ for a perforate sample with $2 \%$ porosity plotted against velocity ratio for excitation at $110 \mathrm{~Hz}$ varied and excitation at $330 \mathrm{~Hz}$ kept constant, from $^{18}$ : black - real part, red - imaginary part, solid line - phase at $330 \mathrm{~Hz}$ not shifted , dashed - phase at 330 Hz shifted 180 degrees, dashed-dotted - phase at $330 \mathrm{~Hz}$ shifted 60 degrees, dotted - phase at $330 \mathrm{~Hz}$ shifted 90 degrees. a) Measured, b) simulation.

Figures 23 and 24 shows simulated results for the impedance of samples P2 and P4 with 2\% and $3.2 \%$ porosity obtained using two tone excitation. Here the impedance at $110 \mathrm{~Hz}$ is presented while the level of excitation at other frequencies $(60,120,220$ and $440 \mathrm{~Hz}$ ) is varied. The phase has been varied from the experimentally obtained particle velocities by either complex conjugating the velocity or adding a phase shift of: $\pi / 2, \pi / 3$ or $\pi / 4$. It can be seen that the phase shift produces a scatter in the reactance results and also in the resistance results at higher levels 
of excitation. It should be noticed that the level of excitation at the other frequencies is high compared to the level of excitation at $110 \mathrm{~Hz}$ for the higher values of summed (total) particle velocity.
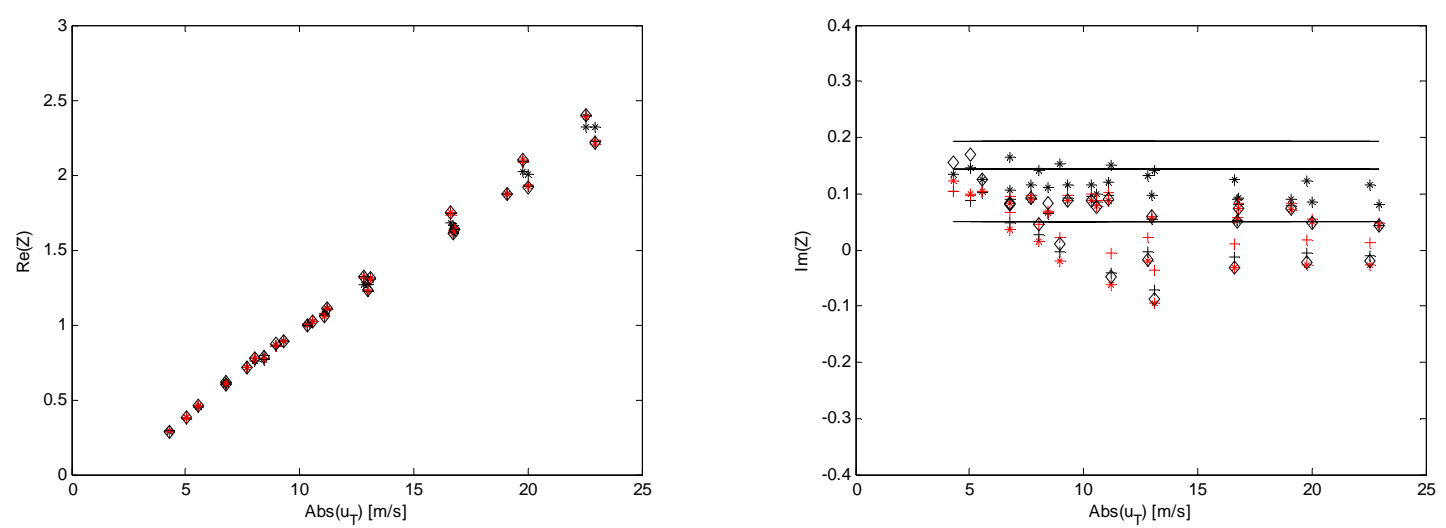

Figure 23. Simulated results for normalised impedance at $110 \mathrm{~Hz}$ for a perforate sample with $3.2 \%$ porosity plotted against summed particle velocity, excitation at $110 \mathrm{~Hz}$ kept constant and excitation at other frequencies varied: black stars - phase at $110 \mathrm{~Hz}$ according to experiments, red stars - phase at $110 \mathrm{~Hz}$ shifted $\pi / 2$, black plus - phase at $110 \mathrm{~Hz}$ shifted $\pi / 3$, red plus - phase at $110 \mathrm{~Hz}$ shifted $\pi / 4$, black diamonds phase at $110 \mathrm{~Hz}$ complex conjugated. a) Real part, b) imaginary part.
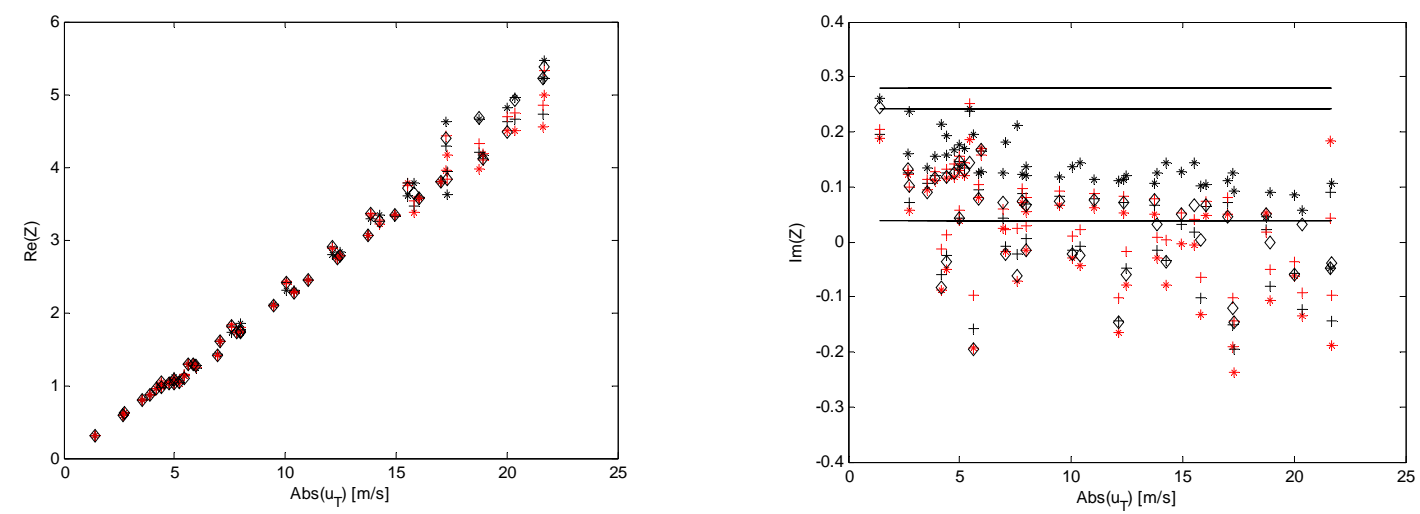

Figure 24. Simulated results for normalised impedance at $110 \mathrm{~Hz}$ for a perforate sample with $2 \%$ porosity plotted against summed particle velocity, excitation at $110 \mathrm{~Hz}$ kept constant and excitation at other frequencies varied: black stars - phase at $110 \mathrm{~Hz}$ according to experiments, red stars - phase at $110 \mathrm{~Hz}$ shifted $\pi / 2$, black plus - phase at $110 \mathrm{~Hz}$ shifted $\pi / 3$, red plus - phase at $110 \mathrm{~Hz}$ shifted $\pi / 4$, black diamonds phase at $110 \mathrm{~Hz}$ complex conjugated. a) Real part, b) imaginary part.

\section{Conclusions}

The result of high level acoustic multi-tone excitation on the acoustic properties of perforates has been investigated experimentally and using a model. It was shown that a modified version of the Cummings ${ }^{7}$ model gives sufficiently good results, for single tone excitation, when compared to experimental data to use the model for parameter variation studies. For two and multi-tone excitation the model gives reasonable results for the resistance while it is less good for the reactance part of the perforate impedance. It was concluded that the combination of frequencies is of importance for multi tone excitation. $\mathrm{In}^{18}$ it was shown that harmonically related tones have a stronger influence on the nonlinear interaction results compared to other combinations of frequencies. Here it was also demonstrated that if the tones used for excitation are nearby in the frequency plane, such as the $110 \mathrm{~Hz}$ and 120 $\mathrm{Hz}$ components used in the present study, the effect on the apparent impedance at these two frequencies will be affected substantially. It was shown just as in $^{18}$ that the phase of the tones used also makes a difference for the result 
especially at higher levels of excitation. $\mathrm{In}^{18}$ it was concluded that no single parameter which controls the obtained impedance results for an arbitrary combination of tones could be found. Here it was shown that plotting the impedance result against the particle velocity at the frequency where the impedance is evaluated rather than against the summed particle velocity for all frequencies gives a better collapse of the measured data especially for the resistance

\section{References}

${ }^{1}$ Sivian I.J., Acoustic impedance of small orifices. Journal of the Acoustical Society of America 7, 1935 ,pp. 94-101.

${ }^{2}$ Ingård, U. and Labate, S., "Acoustic circulation effects and the nonlinear impedance of orifices", Journal of the Acoustical Society of America, Vol. 22, 1950, pp. 211-219.

${ }^{3}$ Ingård, U. and Ising, H., "Acoustic nonlinearity of an orifice", Journal of the Acoustical Society of America, Vol. 42, 1967, pp. 6-17.

${ }^{4}$ Melling, T.H., "The acoustic impedance of perforates at medium and high sound pressure levels”, Journal of Sound and Vibration, Vol. 29, No. 1, 1973, pp. 1-65.

${ }^{5}$ Zinn B.T.. "A theoretical study of nonlinear damping by Helmholtz resonators.” Journal of Sound and Vibration 13, 1970, pp. 347-356.

${ }^{6}$ Cummings A., “Acoustic nonlinearities and power losses at orifices.” AIAA Journal 22(6), 786-792 (1984).

${ }^{7}$ A. Cummings 1986. Journal of the Acoustical Society of America 79, 942-951. Transient and multiple frequency sound transmission through perforated plates at high amplitude.

${ }^{8}$ Salikuddin, M. “Acoustic behaviour of orifice plates and perforated plates with reference to low-frequency sound absorption.” Journal of Sound and Vibration 139, 361-381 (1990).

${ }^{9}$ Salikuddin M. and Brown W.H., "Non-linear effects in finite amplitude wave propagation and perforated plate terminations.” Journal of Sound and Vibration 139, 383-405 (1990).

${ }^{10}$ Panton R.L. and Goldman L., "Correlation of nonlinear orifice impedance.” Journal of the Acoustical Society of America 60, 1390-1396 (1976).

${ }^{11}$ Ingård, U., "Nonlinear distortion of sound transmitted through an orifice", Journal of the Acoustical Society of America, Vol. 48, 1970, pp. 32-33.

${ }^{12}$ Tam, C.K.W. and Kurbatski, K.A., "Micro-fluid dynamics and acoustics of resonant liners”, AIAA Paper, AIAA 99-1850, 1999.

${ }^{13}$ Tam, C.K.W., Kurbatski, K.A., Ahuja K.K.and Gaeta Jr., R.J. “A Numerical and Experimental Investigation of the Dissipation Mechanisms of Resonant Acoustic Liners”, Journal of Sound and Vibration, Vol. 245, No. 3, 2001, pp. 545-557.

${ }^{14}$ Tam, C.K.W., Ju, H., Jones, M.G, Watson, W.R. and Parrott, T.L. “A Computational and Experimental Study of Slit Resonators”, Journal of Sound and Vibration, Vol. 284, No. 3-5, 2005, pp. 947-984.

${ }^{15}$ Elnady, T. and Bodén, H., "On semi-empirical liner impedance modeling with grazing flow”, AIAA Paper, AIAA 2003-3304, May 2003.

${ }^{16}$ Elnady, T., "Modelling and characterization of perforates in lined ducts and mufflers (Paper III)", PhD Thesis, Department of Aeronautical and Vehicle Engineering, KTH, Stockholm, Sweden, 2004.

${ }^{17}$ Bodén, H., Ying, G. and Tözün, H.B., "Experimental investigation of nonlinear acoustic properties for perforates”, AIAA Paper 2006- 2404.

${ }^{18}$ Bodén, H., "The effect of high level multi-tone excitation on the acoustic properties of perforates and liner samples”, AIAA Paper 2012- 2404.

${ }^{19}$ Lahiri C., Pardowitz B., Bake F., Röhle I. and Enghardt L., "Excitation of a Zero Mass Flow Liner for Acoustic Damping”, AIAA Journal, vol. 49, issue 3, pp. 513-519.

${ }^{20}$ Bodén, H. and Zhou , L. "Acoustic properties of an in-duct orifice subjected to bias flow and high level acoustic excitation”, Proceedings of FIV 2012.

${ }^{21}$ Bodén, H. "One-sided multi-port techniques for characterisation of in-duct samples with nonlinear acoustic properties”, Journal of Sound and Vibration, Vol. 331, 2012, pp. 3050-3067. 